\title{
Artificial insemination in Houbara bustards (Chlamydotis undulata): influence of the number of spermatozoa and insemination frequency on fertility and ability to hatch
}

\author{
M. Saint Jalme, P. Gaucher and P. Paillat \\ National Wildlife Research Center (National Commission for Wildlife Conservation and \\ Developments), Taif, PO Box 1086, Saudi Arabia
}

\begin{abstract}
Between 1989 and 1992, artificial insemination was used in the reproduction of two subspecies of Houbara bustard (Chlamydotis undulata macqueenii and Chlamydotis undulata undulata) at the National Wildlife Research Center, Taif. The laying period was between January and July and the mean annual egg production in C. undulata macqueenii was 10.2 and in C. undulata undulata was 7.6. No differences were found in sperm production between the two subspecies: the mean volume of ejaculate was $0.08 \mathrm{ml}$; the mean sperm concentration was $350 \times 10^{6}$ spermatozoa $\mathrm{ml}^{-1}$; and the mean number of spermatozoa per ejaculate was about $20 \times 10^{\circ}$. Large intra- and inter-individual variation was found in sperm parameters. Intra-individual variation in number of spermatozoa per ejaculate was due mainly to seasonal variation. The mean quantity of spermatozoa produced per week by fully sexually mature Houbara bustards was $165 \times 10^{6}$. There was no significant difference in fertility or in ability to hatch between the two subspecies. Overall, in 1992, mean fertility was $69.3 \%$ and $49.2 \%$ of eggs hatched. Females showed a median sperm storage duration of 10 days and a maximum sperm storage duration of 22 days. A positive correlation was found between fertility and quantity of spermatozoa inseminated $(R=0.99, P<0.001)$. Sperm storage duration was related to the number of spermatozoa inseminated. The best results ( $85 \%$ fertile eggs) were obtained when more than $10^{6}$ spermatozoa were inseminated between 3 and 6 days before laying. Analysis of hatching showed that embryo mortality increased when inseminations were performed more than 10 days before laying.
\end{abstract}

\section{Introduction}

There are three subspecies of Houbara bustard, Chlamydotis. The subspecies Chlamydotis undulata undulata inhabits the North African range; Chlamydotis undulata fuertaventurae lives only on the Canary Islands; and C. undulata macqueenii is found from Sinai eastwards, probably including the eastern edge of the Nile Valley where it may live sympatrically with $C . u$. undulata (Cramp and Simmons, 1980).

During recent decades, populations of Houbara bustards have declined dramatically over their entire distribution. Concern over the threat of extinction of local populations was an important factor leading to the establishment of a captive breeding unit in Taif, Saudi Arabia, with the aim of producing sufficient birds for eventual reintroduction or restocking of local populations.

Very little is known about the reproductive biology of the species or the feasibility of producing a large number of chicks. Mating tends to be most frequent during the spring months but the timing varies across the range of the species (Heim De Balzac and Mayaud, 1962; Dementiev and Gladkov, 1968; Cramp and Simmons, 1980). In Algeria, eggs are found as early

Received 1 March 1993. as November or as late as June (Cramp and Simmons, 1980). The Houbara bustard is known to lay between one and four eggs on alternate days (Heim De Balzac and Mayaud, 1962; Etchecopar and Hue, 1978; Mendelssohn, 1980; Urban et al., 1986). According to Cramp and Simmons (1980), wild Houbara bustards lay one clutch a year but may lay a replacement clutch if the first clutch is lost.

Two of the three subspecies C. $u$. undulata and C. $u$. macqueenii are captive bred at Taif. The first breeding success was achieved in 1989 with the production of 17 chicks. After this, 55 and 49 chicks were produced in 1990 and 1991, and 138 in 1992. Poor results obtained from natural mating resulting in a maximum of $30 \%$ fertile eggs prompted the use of artificial insemination techniques.

Artificial insemination is a very convenient tool in the captive breeding of endangered birds, especially when natural mating does not yield acceptable results. Artificial insemination has been successful in domestic birds such as turkey, guineafowl, chicken, mallard and goose (Sauveur, 1988), but relatively few studies have been published on non-domesticated birds. Before a method for efficient artificial insemination can be developed, it is necessary to establish: (1) the ability of the male to produce spermatozoa; (2) the minimum quantity of 
Table 1. Composition of the breeding stock of Houbara bustards (Chlamydotis undulata) from 1989 to 1992

\begin{tabular}{ccccc}
\hline Year & $\begin{array}{c}\text { Chlamydotis } \\
\text { undulata macqueenii }\end{array}$ & \multicolumn{2}{c}{$\begin{array}{c}\text { Chlamydotis } \\
\text { undulata undulata }\end{array}$} \\
\hline & Males & Females & Males & Females \\
1989 & 34 & 35 & 43 & 47 \\
1990 & 43 & 47 & 34 & 45 \\
1991 & 43 & 45 & 30 & 40 \\
1992 & 39 & 48 & 39 & 47 \\
\hline
\end{tabular}

spermatozoa to be inseminated without reducing fertility; and (3) the timing of insemination in relation to the timing of laying. Insemination of poultry performed less than $5 \mathrm{~h}$ before or after oviposition is unlikely to produce fertilized eggs (Brillard, 1982). Sperm storage duration is usually defined as the interval between the last insemination and the laying of the last fertile egg (Lake, 1975). Sperm storage duration is an important component of the fertile period of the female and, in practice, must determine the frequency of insemination (Brillard, 1982).

This study presents observations on the artificial insemination of the Houbara bustard, an endangered species. After investigating the annual reproductive cycle and reproductive capacities of Houbara bustards in captivity, the sperm production (volume of the semen, sperm concentration and number of spermatozoa per ejaculate) and the response of the female to artificial insemination (sperm storage duration, effect of quality of the semen on fertility and hatching levels) were investigated.

\section{Materials and Methods}

\section{Location and time of the study}

The study was conducted at the National Wildlife Research Center of Taif $\left(21.15^{\circ} \mathrm{N}, 40.41^{\circ} \mathrm{E}\right.$; altitude: $\left.1450 \mathrm{~m}\right)$ in Saudi Arabia between 1989 and 1992 .

\section{Animals}

The breeding stock (Table 1 ) originated from eggs collected in Pakistan (Chlamydotis undulata macqueenii) and in Algeria (Chlamydotis undulata undulata). Birds obtained from private collections were also added to the initial breeding flock. The birds, aged between 2 and 10 years, were kept in individual outdoor $(6 \mathrm{~m} \times 4 \mathrm{~m} \times 2.3 \mathrm{~m})$ pens from January to August and in heterosexual groups (10 males and 10 females) for the remainder of the year. Food and water were provided ad libitum.

From January to July, males were checked for display twice a day. Female cages were checked four times a day to collect the eggs.

\section{Collection of spermatozoa}

Collecting semen was only possible for males that were raised by hand after hatching.
A dummy female was presented to a displaying male. The male approached, performing the precopulation display and pecked the dummy's head before mounting and copulating with it. A glass dish is used to collect the semen by holding it under the male's cloaca during ejaculation. The semen was then immediately transferred to a $1 \mathrm{ml}$ vial which contained $0.2 \mathrm{ml}$ of commercial diluent (guineafowl diluent: IMV, Laigle). In 1992, a total of 489 samples of spermatozoa was collected from 24 males (13 C. u. undulata and 11 C. u. macqueenii).

The effect of frequency of semen collection on the number of spermatozoa ejaculated was analysed, by collecting semen once a day (all spermatozoa collected following one collection the day before), once every 2 days and once every 3 days (all spermatozoa collected after one collection 2 days and 3 days before), and less frequently than once every 3 days (all spermatozoa collected when no other collection was performed in at least the previous 3 days).

\section{Sperm analysis}

Immediately after collection, semen was brought to the laboratory and analysed for concentration and motility of spermatozoa. Between 1989 and 1991, sperm quality was assessed empirically using a microscope. When a sample of semen was considered good in relation to concentration and motility of spermatozoa compared with the average quality observed, it was used for insemination.

In 1992, a quantitative study was undertaken. Semen was collected in $0.2 \mathrm{ml}$ of diluent. Once in the laboratory, $0.02 \mathrm{ml}$ of the solution of ejaculate and diluent was diluted tenfold for analysis of sperm concentration, number of spermatozoa per ejaculate and motility of spermatozoa. A Thomas' cell was used for these analyses. This cell is divided into a grid of $6.25 \times 10^{-5} \mathrm{~mm}^{2}$ grouped into larger squares $(0.2 \mathrm{~mm} \times 0.2 \mathrm{~mm})$.

The number of spermatozoa in six large squares was determined and the mean value used.

The total number of spermatozoa per ejaculate was calculated by using the following formula: total number of spermatozoa per ejaculate $=$ number of spermatozoa per square $\times 250 \times 10^{3} \times$ (volume of ejaculate and diluent in $\mathrm{ml}) \times 10$. The concentration of spermatozoa $\mathrm{ml}^{-1}$ was then calculated as the number of spermatozoa per ejaculate divided by the total volume of semen ejaculated. The volume of semen was estimated using a graduated tube with a precision of $\pm 0.01 \mathrm{ml}$.

The motility of spermatozoa was determined on the following scale: (1) no motility, (2) less than $50 \%$ of spermatozoa showing activity, (3) more than $50 \%$ of the spermatozoa motile but the majority of individual tracks only circular and local and (4) more than $80 \%$ of the spermatozoa motile and individual movement spread over several counting squares. Empirically it was decided to inseminate only semen with a motility coefficient above 2 .

\section{Insemination}

Insemination was performed in the morning between 07:00 $\mathrm{h}$ and 10:00 h. The semen was inseminated within 
$30 \mathrm{~min}$ after collection. The insemination procedure was as follows: the cloaca was opened using special forceps; an insemination tube mounted on a syringe was inserted about $1 \mathrm{~cm}$ inside the vagina, and was emptied slowly by applying gentle pressure on the piston. Between 1989 and 1992, 706 inseminations were performed at intervals of 3-30 days before laying and analysed to investigate sperm storage duration inside the female reproductive tract. In this analysis, the number of spermatozoa inseminated was not taken into account.

In 1992, a total of 52 females was inseminated producing a total of 371 eggs. A total of 815 inseminations was performed. Intervals between two inseminations were four days (35\%) between 5 and 7 days $(51 \%)$ and between 8 and 15 days $(14 \%)$. By these procedures, during the 15 days before laying, females received between one and three inseminations. The quantity of spermatozoa inseminated ranged for each insemination from 1 to $50 \times 10^{6}$.

The duration of sperm storage was estimated by defining three different parameters: mean, median and maximum sperm storage duration (Birkhead and Moller, 1992). From our analyses, the median and maximum sperm storage durations were calculated. The median is calculated by plotting the fertility curve, the proportion of fertile eggs in relation to time since the last insemination, and recording the point at which $50 \%$ of eggs are no longer fertile. The maximum value is the single longest sperm storage duration recorded (Birkhead, 1988).

The effect of number of spermatozoa inseminated on fertility was estimated by adding the quantity of spermatozoa inseminated before laying for the following intervals: $3-6$ days before laying, 3-10 days and 3-15 days.

\section{Incubation}

Eggs were incubated in small incubators each containing 25 eggs. Incubation temperature was $37.7^{\circ} \mathrm{C}$ and humidity was adjusted to allow a theoretical mass loss of $17 \%$ during incubation. Under these conditions, the mean incubation time was 22 days.

Stages of embryo development were estimated by candling eggs twice a week. When embryos were found to be dead, the eggs were removed and opened to evaluate the age at which they died.

\section{Results}

\section{Seasonal cycle of reproduction}

In 1992, the first Chlamydotis undulata macqueenii egg was laid on the 20 January, three weeks after the transfer of birds to the breeding pens. The first female Chlamydotis undulata undulata laid two weeks later. C. u. macqueenii mated earlier and showed earlier gonadal regression than did C. u. undulata (Fig. 1a) (Mann-Whitney test: $P<0.001$ ), but a large overlap was observed in the laying periods of both subspecies.

The majority of males displayed from December to July but some were observed displaying almost throughout the whole year (Fig. Ib). Maximum numbers of displays were observed 2 weeks before the peak of laying and the display cycles of the two subspecies were synchronous.
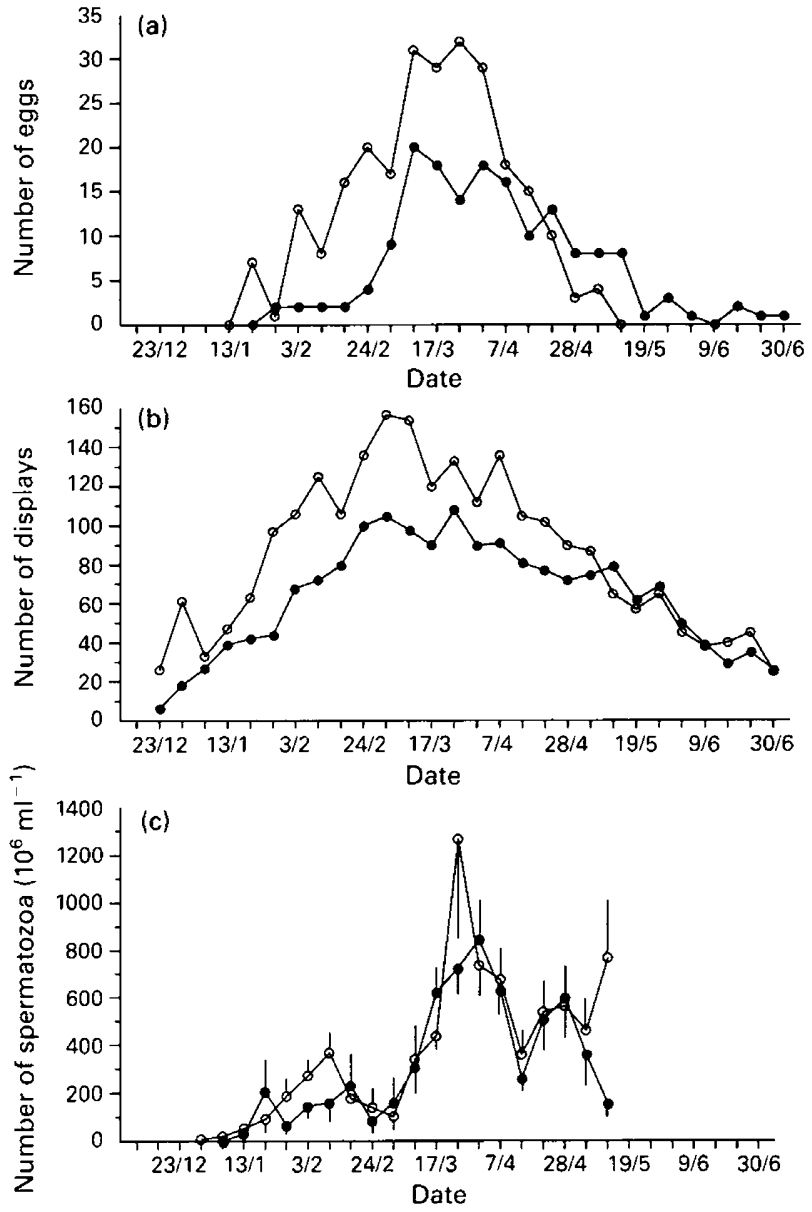

Fig. 1. Seasonal variation of laying in Houbara bustards (Chlamydotis undulata) (a) total number of eggs laid per week, (b) total number of displaying days per week (one male displaying on at least one occasion per day was recorded as 1 display) and (c) mean sperm concentration \pm SEM. (O) C. u. macqueenii, (O) C. u. undulata.

The concentration of spermatozoa (Fig. Ic) followed a similar pattern to that observed for laying and display. It was of interest to note that the maximum sperm concentration was synchronous with the laying peak, but occurred 2 weeks later than the peak of display. The pattern of seasonal variation of sperm concentration was exactly the same in the two subspecies. The decreases in sperm concentration between the first and the last week of February approached significance (Students $t$ test: $d . f .=28, t=1.92, P=0.06$ ) and the decrease during the second week of April, in the middle of the peak, was significant ( $d . f .=36, t=3.47, P=0.0014)$. This decline in sperm production was synchronous with a peak in ambient temperature.

\section{Reproductive parameters}

Between 1988 and 1992, we recorded the age of sexual maturity of both subspecies. Only $25 \%$ of females laid at two years of age; $65 \%$ laid when three years old; and $85 \%$ laid at the age of four. Males reproduced earlier than females with 
Table 2. Comparison between reproductive parameters of two subspecies of Houbara bustard Chlamydotis undulata macqueenii and Chlamydotis undulata undulata

\begin{tabular}{|c|c|c|c|c|c|c|c|}
\hline \multirow[b]{2}{*}{ Parameter } & \multicolumn{3}{|c|}{ Chlamydotis undulata macqueenii } & \multicolumn{3}{|c|}{ Chlamydotis undulata undulata } & \multirow[b]{2}{*}{ Probability } \\
\hline & $n$ & Mean \pm SD & Range & $n$ & Mean $\pm \mathrm{SD}$ & Range & \\
\hline Number of eggs laid & 28 & $10.2 \pm 6.5$ & $(1-26)$ & 23 & $7.6 \pm 4.3$ & $(1-19)$ & 0.155 \\
\hline Clutch size & 131 & $2.2 \pm 1.0$ & $(1-7)$ & 91 & $1.8 \pm 0.6$ & $(1-3)$ & 0.003 \\
\hline Number of clutches & 28 & $4.7 \pm 2.3$ & $(1-8)$ & 23 & $4.5 \pm 1.9$ & $(1-9)$ & 0.520 \\
\hline Inter-clutch interval & 100 & $8.7 \pm 2.3$ & $(5-17)$ & 60 & $11.9 \pm 4.6$ & $(5-27)$ & 0.000 \\
\hline Number of days of display by male & 30 & $71.5 \pm 53.8$ & $(1-186)$ & 28 & $64.2 \pm 57.3$ & $(1-172)$ & 0.479 \\
\hline
\end{tabular}

Mean number of eggs laid by 28 C. u. macqueenii and 23 C. u. undulata, mean clutch size calculated on 131 and 91 clutches, mean number of clutches per female calculated on 28 and 23 females, mean inter-clutch interval on 100 and 60 intervals between clutches and mean number of day of display calculated on 30 males C. u. macqueenii and 28 C. u. undulata.

Table 3. Nyctemeral distribution of time of oviposition for 468 eggs laid in 1992 by 29 female Chlamydotis undulata undulata and 31 female Chlamydotis undulata macqueenii

\begin{tabular}{lllllllllllll}
\hline & \multicolumn{10}{c}{ Time of day (h) } \\
\cline { 2 - 11 } Parameter & $13-14$ & $14-15$ & $15-16$ & $16-17$ & $17-18$ & $18-07$ & $07-08$ & $08-09$ & $09-10$ & $10-11$ & $11-12$ & $12-13$ \\
\hline Number of eggs & 4 & 5 & 24 & 38 & 71 & 322 & 0 & 2 & 0 & 1 & 1 \\
Percentage of eggs & 0.9 & 1.1 & 5.1 & 8.1 & 15 & 68.8 & 0 & 0.5 & 0 & 0.3 & 0.3 & 0 \\
\hline
\end{tabular}

$40 \%$ displaying at the age of one, and $90 \%$ at the age of two years.

For birds older than 3 years in captivity, when eggs were collected every day and females were not permitted to incubate, the mean number of eggs laid by females was 10.2 in C. u. macqueenii ( $n=28$ females) and 7.6 in C. u. undulata ( $n=23$ females); the difference between the two subspecies was not significant (Table 2). The maximum number of eggs laid by a single female in one reproductive season was 26 for C. u. macqueenii and 19 for C. u. undulata.

Clutch size and inter-clutch interval were determined on the assumption that two eggs separated by less than five days belonged to the same clutch. Within a clutch, eggs were laid on alternate days in $80 \%$ of cases and in the remaining $20 \%$ were spread over 3-4 days. In such cases, we considered that stress or other environmental factors were responsible for delayed oviposition or yolk resorption.

The average clutch size was significantly greater in C. u. macqueenii $(n=131$ clutches, mean $=2.2 \pm 1$ ) than in C. u. undulata ( $n=91$ clutches, mean $=1.8 \pm 0.6$ ) (MannWhitney test: $P=0.003$ ). In $C$. $u$. macqueenii, $68 \%$ of the clutches comprised one or two eggs and $30 \%$ three or four (a five egg clutch occurred on two occasions and a seven egg clutch on one occasion). In C. u. undulata, $80 \%$ of clutches consisted of one or two eggs. A clutch with more than three eggs was never recorded.

The interval between clutches was significantly greater in C. $u$. undulata ( $n=60$ intervals, mean $=11.9 \pm 4.6$ days) than in C. u. macqueenii ( $n=100$ intervals, mean $=8.7 \pm 2.3$ days; Mann-Whitney test: $P<0.001$ ). The mean number of clutches laid by females of the two subspecies was very similar (between four and five) and a maximum of nine clutches was laid between the end of January and the beginning of June.

The duration of the displaying period varied between males. No significant difference was found between $C$. $u$. macqueenii ( $n=30$ males) and C. u. undulata $(n=28$ males) and a large inter-individual variability was observed (range: 1-186 days of display).

\section{Time of laying}

In 1992, the time of laying was recorded for 468 eggs (Table 3). There was no significant difference between the two subspecies, and the data were combined. During the laying season, sunset occurred between 18:00 h and 19:00 h and sunrise between 05:30 $\mathrm{h}$ and 06:30 $\mathrm{h}$. One per cent of eggs was laid in the morning after sunrise, $30 \%$ was laid between $15: 00 \mathrm{~h}$ and $18: 00 \mathrm{~h}$ and a large proportion (69\%) after sunset. For the last mentioned group, it was not possible to record the precise time of laying. In many cases when a clutch of two or more eggs was laid, the first egg was laid at the end of the afternoon and a shift in laying time was observed on successive days.

\section{Sperm production}

For all sperm production parameters recorded there was great inter- and intra-individual variability (Tables 4 and 5) and no significant difference was found between the subspecies. The mean volume of ejaculate recorded was between 0.07 and $0.08 \mathrm{ml}$, ranging between 0.01 and $0.30 \mathrm{ml}$. The mean concentration of spermatozoa was about $350 \times 10^{6}$ 
Table 4. Sperm parameters for 13 Chlamydotis undulata undulata

\begin{tabular}{|c|c|c|c|c|c|c|}
\hline \multirow{2}{*}{$\begin{array}{l}\text { Number of } \\
\text { semen samples }\end{array}$} & \multicolumn{2}{|c|}{ Volume ejaculated (ml) } & \multicolumn{2}{|c|}{ Sperm concentration $\left(\times 10^{6} \mathrm{ml}^{-1}\right)$} & \multicolumn{2}{|c|}{ Number of spermatozoa $\left(\times 10^{6}\right)$ per ejaculate } \\
\hline & Mean \pm SD & Range & Mean $\pm \mathrm{SD}$ & Range & Mean \pm SD & Range \\
\hline 1 & 0.05 & - & 1350 & - & 67.5 & - \\
\hline 28 & $0.05 \pm 0.02$ & $(0.01-0.10)$ & $985 \pm 582$ & $(175-2100)$ & $48.7 \pm 32.6$ & $(8.7-120)$ \\
\hline 1 & 0.05 & - & 857 & - & 42.9 & - \\
\hline 36 & $0.08 \pm 0.03$ & $(0.01-0.15)$ & $436 \pm 248$ & $(25-1108)$ & $30.6 \pm 18.3$ & $(1.2-72.5)$ \\
\hline 11 & $0.05 \pm 0.02$ & $(0.02-0.10)$ & $380 \pm 477$ & $(3-1160)$ & $18.6 \pm 22.7$ & $(13-67.9)$ \\
\hline 8 & $0.08 \pm 0.04$ & $(0.05-0.15)$ & $361 \pm 297$ & $(82-880)$ & $27.0 \pm 22.6$ & $(7.1-61.5)$ \\
\hline 10 & $0.06 \pm 0.02$ & $(0.02-0.10)$ & $283 \pm 336$ & $(12-1100)$ & $18.9 \pm 22.8$ & $(0.60-66.0)$ \\
\hline 14 & $0.07 \pm 0.04$ & $(0.01-0.15)$ & $239 \pm 286$ & $(29-998)$ & $11.5 \pm 11.6$ & $(0.90-39.0)$ \\
\hline 40 & $0.13 \pm 0.06$ & $(0.01-0.23)$ & $171 \pm 160$ & $(10-890)$ & $20.1 \pm 17.9$ & $(0.50-83.6)$ \\
\hline 13 & $0.10 \pm 0.05$ & $(0.03-0.17)$ & $83 \pm 102$ & $(23-390)$ & $6.5 \pm 6.0$ & $(0.90-19.5)$ \\
\hline 8 & $0.07 \pm 0.03$ & $(0.02-0.13)$ & $76 \pm 55$ & $(25-200)$ & $4.7 \pm 3.2$ & $(1.1-10.0)$ \\
\hline 9 & $0.09 \pm 0.07$ & $(0.02-0.25)$ & $19 \pm 16$ & $(3-55)$ & $1.4 \pm \quad 1.5$ & $(0.10-4.60)$ \\
\hline 11 & $0.08 \pm 0.05$ & $(0.01-0.15)$ & $4 \pm \quad 8$ & $(0.3-27)$ & $0.2 \pm \quad 0.4$ & $(0.05-1.40)$ \\
\hline \multicolumn{7}{|l|}{ Total } \\
\hline 190 & $0.08 \pm 0.05$ & $(0.01-0.25)$ & $369 \pm 436$ & $(0.3-2100)$ & $23.4 \pm 24.2$ & $(0.05-120)$ \\
\hline
\end{tabular}

Table 5. Sperm parameters for 11 Chlamydotis undulata macqueenit

\begin{tabular}{|c|c|c|c|c|c|c|}
\hline \multirow{2}{*}{$\begin{array}{l}\text { Number of } \\
\text { semen samples }\end{array}$} & \multicolumn{2}{|c|}{ Volume ejaculated $(\mathrm{ml})$} & \multicolumn{2}{|c|}{ Sperm concentration $\left(\times 10^{6} \mathrm{ml}^{-1}\right)$} & \multicolumn{2}{|c|}{ Number of spermatozoa $\left(\times 10^{6}\right)$ per ejaculate } \\
\hline & Mean \pm SD & Range & Mean \pm SD & Range & Mean \pm SD & Range \\
\hline 7 & $0.05 \pm 0.04$ & $(0.01-0.13)$ & $1609 \pm 1576$ & $(15-4515)$ & $56.0 \pm 47.0$ & $(0.80-134)$ \\
\hline 61 & $0.06 \pm 0.04$ & $(0.01-0.20)$ & $791 \pm 728$ & $(1.0-4180)$ & $40.6 \pm 30.5$ & $(0.10-156)$ \\
\hline 4 & $0.18 \pm 0.12$ & $(0.02-0.26)$ & $595 \pm 302$ & $(261-990)$ & $70.1 \pm 74.5$ & $(10.4-168)$ \\
\hline 34 & $0.05 \pm 0.02$ & $(0.01-0.10)$ & $431 \pm 464$ & $(0.2-1800)$ & $17.2 \pm 15.4$ & $(0.01-57.4)$ \\
\hline 24 & $0.05 \pm 0.03$ & $(0.01-0.13)$ & $401 \pm 384$ & $(6.0-1620)$ & $33.0 \pm 81.0$ & $(0.30-405)$ \\
\hline 29 & $0.08 \pm 0.03$ & $(0.04-0.15)$ & $231 \pm 155$ & $(30-712)$ & $17.6 \pm 13.0$ & $(3.0-50)$ \\
\hline 35 & $0.08 \pm 0.05$ & $(0.01-0.18)$ & $184 \pm 143$ & $(6.0-550)$ & $11.9 \pm 10.3$ & $(0.30-50.1)$ \\
\hline 19 & $0.08 \pm 0.04$ & $(0.02-0.15)$ & $152 \pm 185$ & $(6.0-624)$ & $16.0 \pm 14.0$ & $(0.60-47)$ \\
\hline 14 & $0.07 \pm 0.04$ & $(0.01-0.15)$ & $85 \pm 93$ & $(0.2-347)$ & $5.9 \pm 5.2$ & $(0.0 I-15)$ \\
\hline 35 & $0.08 \pm 0.06$ & $(0.01-0.30)$ & $83 \pm$ & $(0.2-380)$ & $6.0 \pm 7.0$ & $(0.01-30)$ \\
\hline 37 & $0.09 \pm 0.07$ & $(0.01-0.30)$ & $70 \pm$ & $(0.2-430)$ & $6.2 \pm 6.6$ & $(0.01-21.5)$ \\
\hline \multicolumn{7}{|l|}{ Total } \\
\hline 299 & $0.07 \pm 0.05$ & $(0.01-0.30)$ & $343 \pm 478$ & $(0.2-4515)$ & $19.6 \pm 24.4$ & $(0.01-405)$ \\
\hline
\end{tabular}

spermatozoa $\mathrm{ml}^{-1}$, ranging between $0.3 \times 10^{6}$ and $4515 \times 10^{6}$. Despite large intra-individual variation, inter-individual differences were significant (ANOVA: $d . f .=21, F=13.19, P<0.001$ ). Individual mean sperm concentrations fluctuated between $1609 \times 10^{6}$ and $4 \times 10^{6}$ spermatozoa $\mathrm{ml}^{-1}$.

The number of spermatozoa per ejaculate was directly related to sperm concentration. A good correlation $(R=0.87$, $P<0.001$ ) occurred with individuals between mean sperm concentration and mean number of spermatozoa per ejaculate. The average number of spermatozoa per ejaculate was about $20 \times 10^{6}$. As for sperm concentration, large intra- and interindividual variation was found, with values ranging from 10000 to $405 \times 10^{6}$ spermatozoa per ejaculate.
Intra-individual variation in the number of spermatozoa per ejaculate was due largely to seasonal variation (Fig. 2). Between the beginning of January and the end of February, the mean number of spermatozoa per ejaculate remained relatively low (less than $20 \times 10^{6}$ spermatozoa per semen sample). The number of spermatozoa collected increased rapidly during the first 15 days of March (between 3 March and 10 March: Student's $t$ test: d.f. $=56, t=-2.03, P=0.047$ ) and remained high until the third week of May. The number of spermatozoa per ejaculate decreased abruptly between 5 May and 19 May (Student's $t$ test: $d . f .=11, t=2.41, P=0.034$ ). The decrease in April, at the middle of the peak, was significant (d.f. $=47$, $t=2.96, P=0.0048$ ). 


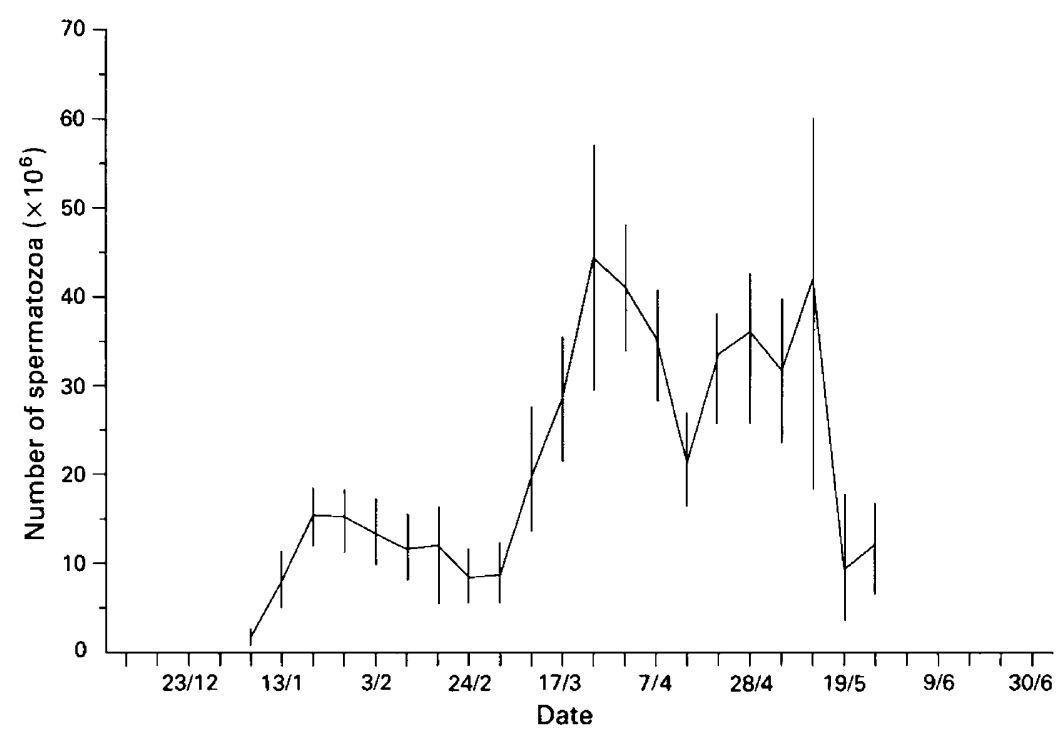

Fig. 2. Seasonal variation of number of spermatozoa collected per ejaculate (mean \pm SEM) in Houbara bustards (Chlamydotis undulata).

Table 6. Relationship between sperm collection frequency and number of spermatozoa per ejaculate in Houbara bustards (Chlamydotis undulata)

\begin{tabular}{lccc}
\hline $\begin{array}{l}\text { Number of } \\
\text { collections } \\
\text { from all males }\end{array}$ & $\begin{array}{c}\text { Sperm } \\
\text { collection } \\
\text { frequency }\end{array}$ & $\begin{array}{c}\text { Number of spermatozoa } \\
\text { per ejaculate } \\
\left(\times 10^{6}\right) \pm S D\end{array}$ & $\begin{array}{c}\text { Estimation of } \\
\text { number of } \\
\text { spermatozoa collected } \\
\text { per week }\end{array}$ \\
\hline 87 & $1 /$ day & $23.6 \pm 20.1$ & $165 \times 10^{6}$ \\
62 & $1 / 2$ days & $30.6 \pm 29.5$ & $107 \times 10^{6}$ \\
26 & 13 days & $39.1 \pm 32.0$ & $91 \times 10^{6}$ \\
50 & $1 />3$ days & $37.3 \pm 27.0$ & \\
\hline
\end{tabular}

d.f. $=3, F=4.13, P=0.007$.

Effect of sperm collection frequency on number of spermatozoa ejaculated

Bias due to seasonal variation was avoided by using only data from semen collected during the peak of sperm production, between 10 March and 15 May.

The number of spermatozoa collected per week increased with sperm collection frequency (Table 6). However, the number of spermatozoa per ejaculate increased when sperm collection frequency decreased from one collection per day to one collection every 3 days (ANOVA: d.f. $=3, F=4.13$, $P=0.007)$.

\section{Artificial insemination}

Embryos that died during the first 2 days of development were separated from the others (Table 7). The main reason for separating these data was difficulties in classifying the fertility status at this stage, since bacterial contamination can give the appearance of early death in an infertile egg. Despite this, the fertility given was calculated from all eggs estimated as fertile, including early embryonic failure.
The ability of eggs to hatch was determined using only eggs with an intact egg shell, as full embryonic development is not possible in eggs with cracked shells.

No significant differences were found in fertility or ability of eggs to hatch between the two subspecies. In 1992, overall fertility was $69.3 \%$ and $49.2 \%$ of eggs hatched. If early embryonic failure was excluded, fertility was overcalculated by up to $3.3 \%$ and ability of eggs to hatch undercalculated by as much as $6.5 \%$. Fertility was thus $66 \%$ and ability of eggs to hatch was $55.7 \%$.

Estimation of sperm storage duration within the oviduct

As no difference in sperm storage duration was found between both subspecies, data were combined in the following analysis. Median sperm storage duration was 10 days and maximum sperm storage duration 22 days. Fertility decreased with increasing interval between insemination and laying (Fig. 3). There was evidence that eggs could not be fertilized if insemination was performed less than 3 days before laying. The best fertility results were obtained when insemination occurred 
Table 7. Artificial insemination results calculated from 371 eggs laid in 1992 by 28 female Chlamydotis undulata macqueenii and 24 female Chlamydotis undulata undulata

\begin{tabular}{lccc}
\hline Parameter & Chlamydotis undulata macqueenii & Chlamydotis undulata undulata & Total \\
\hline Number of females inseminated & 28 & 24 & 52 \\
Number of eggs & 228 & 143 & 371 \\
Number of fertile eggs & 150 & 107 & 257 \\
Fertility level & $65.8 \%$ & $74.8 \%$ & $69.3 \%$ \\
Fertile eggs, broken & 1 & 6 & 7 \\
Dead embryo $<3$ days & 22 & 14 & 36 \\
Dead embryo $>2$ days & 56 & 35 & 91 \\
Number of chicks hatched & 71 & 52 & 123 \\
Level of hatching & $47.7 \%$ & $51.5 \%$ & $49.2 \%$ \\
\end{tabular}

Fertility level: number of fertile eggs/number of eggs; level of hatching: number of chicks hatched/(number of fertile eggs - number of broken eggs).

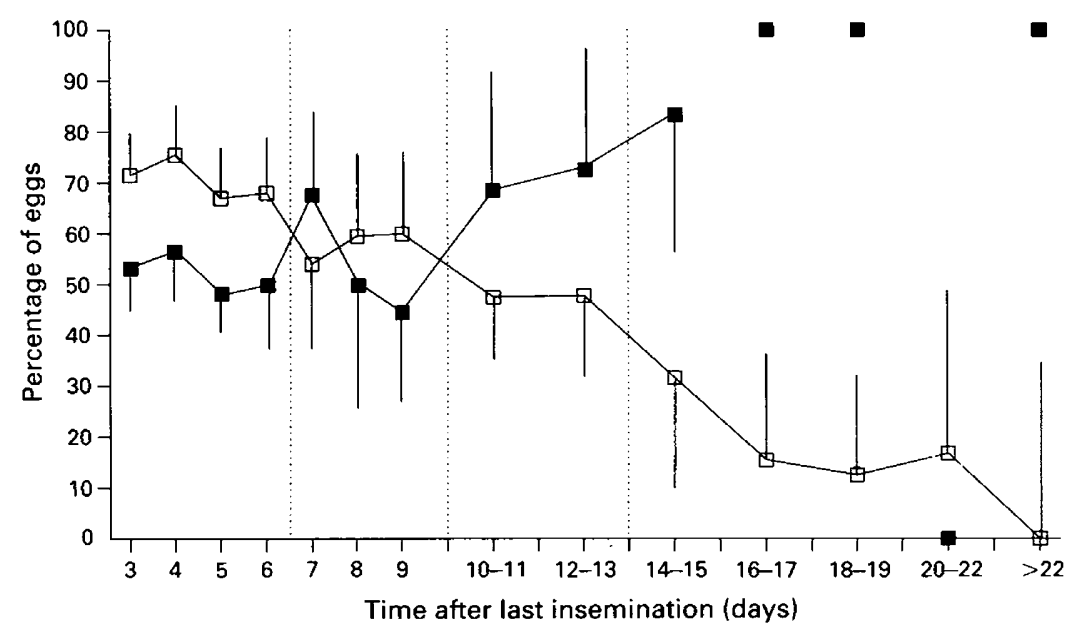

Fig. 3. Effect of sperm storage duration in vivo on fertility and embryo mortality $(\% \pm 95 \%$ confidence interval) in Chlamydotis undulata. ( $\square$ ) Fertility; ( $\square$ ) embryo mortality $(n=706$ eggs).

4 days before laying (75.5\%). There was no significant difference between 3 and 6 days. Between 7 and 9 days, fertility remained at about $60 \%$ (3-6 days versus $7-9$ days: $\chi^{2}=14.4$, $P<0.001$ ). After a delay of 10 days between insemination and laying, fertility decreased to less than $50 \%$ ( $7-9$ days versus $10-13$ days: $\chi^{2}=1.64, P=0.2 ; 10-13$ days versus $>14$ days: $\chi^{2}=10.5, P<0.002$ ).

There was a relationship between embryo mortality and the interval between insemination and laying. No significant differences were found when inseminations occurred less than 10 days before laying. When inseminations were performed more than 10 days before laying, an increase in embryo mortality was observed (when comparing 3-10 days with more than 10 days: $\chi^{2}=5.6, P=0.02$ ).

These results were supported in 1992 (Table 8) when only inseminations of more than $10 \times 10^{6}$ spermatozoa, inseminated before $6,10,15$ and 20 days before laying were performed. An increase in embryo mortality was observed when $10 \times 10^{6}$ spermatozoa were inseminated from 6 to 20 days before laying
( $P=0.001$ when embryo mortality up to 2 days was included and $P=0.029$ when all the fertile eggs were taken into account).

\section{Effect of number of spermatozoa inseminated on fertility}

The 335 eggs obtained in 1992 (of 371, 36 embryos died in the first 2 days of incubation) were classified according to the number of spermatozoa inseminated, with a cluster interval of $5 \times 10^{6}$ spermatozoa. Three analyses were performed (Table 9). The number of spermatozoa inseminated was added for each of the three intervals of time before laying: 3-6 days, 3-10 days and 3-15 days. The percentage of fertile eggs was calculated from all of the eggs for each of the three time periods analysed.

For each interval analysed, an increase in fertility was recorded with increasing number of spermatozoa inseminated (3-6 days: $\chi^{2}=31.8, \quad P<0.001 ; 3-10$ days: $\chi^{2}=31.1$, $P<0.001 ; 3-15$ days: $\left.\chi^{2}=48.7, P<0.001\right)$. The difference in 
Table 8. Relationship between sperm storage duration 'in vitro' and embryo mortality in Houbara bustards (Chlamydotis undulata)

\begin{tabular}{|c|c|c|c|c|}
\hline \multirow[b]{2}{*}{ Embryo mortality } & \multicolumn{4}{|c|}{ More than $\times 10^{6}$ spermatozoa inseminated before: } \\
\hline & 6 days & 10 days & 15 days & 20 days \\
\hline Hatched & 65 & 26 & 17 & 15 \\
\hline Dead $>2$ days & 32 & 23 & 25 & 11 \\
\hline Dead $<3$ days & 12 & 9 & 8 & 7 \\
\hline $\begin{array}{l}\text { Embryo mortality } \\
\text { including dead }<3 \text { days }\end{array}$ & $40.6 \%$ & $\begin{array}{l}55.2 \% \\
\chi^{2}=16\end{array}$ & $\begin{array}{c}66 \% \\
P=0.001\end{array}$ & $54.5 \%$ \\
\hline $\begin{array}{l}\text { Embryo mortality } \\
\text { excluding dead }<3 \text { days }\end{array}$ & $33 \%$ & $\begin{array}{l}46.9 \% \\
\chi^{2}=8.9\end{array}$ & $\begin{array}{c}59.5 \% \\
P=0.029\end{array}$ & $42.3 \%$ \\
\hline
\end{tabular}

Table 9. Relationship between number of spermatozoa inseminated during three intervals of time before laying and fertility of the eggs in percentage of fertile eggs in Houbara bustards (Chlamydotis undulata)

\begin{tabular}{|c|c|c|c|c|c|c|}
\hline \multirow{3}{*}{$\begin{array}{l}\text { Number of spermatozoa } \\
\text { inseminated }\left(\times 10^{6}\right)\end{array}$} & \multicolumn{6}{|c|}{ Percentage of fertile eggs } \\
\hline & \multicolumn{2}{|c|}{ Interval 3-15 days } & \multicolumn{2}{|c|}{ Interval $3-10$ days } & \multicolumn{2}{|c|}{ Interval 3-6 days } \\
\hline & $n$ & $\%$ & $n$ & $\%$ & $n$ & $\%$ \\
\hline $0-5$ & 25 & 28.0 & 71 & 45.1 & 148 & 50.7 \\
\hline $5-10$ & 45 & 46.7 & 71 & 56.3 & 67 & 68.7 \\
\hline $10-15$ & 56 & 51.8 & 51 & 68.0 & 46 & 82.6 \\
\hline $15-20$ & 33 & 60.6 & 32 & 68.8 & 34 & 82.4 \\
\hline$>20$ & 176 & 81.8 & 110 & 82.7 & 40 & 85.0 \\
\hline
\end{tabular}

$n=$ Number of eggs.

fertility in relation to the quantity of spermatozoa inseminated was observed to increase with the number of inseminations. When insemination of more than $10 \times 10^{6}$ spermatozoa occurred during the 6 days before laying, no difference in fertility was observed. When inseminations performed during the 10 days before laying were considered, fertility decreased for inseminations of less than $20 \times 10^{\circ}$, but there was no difference in fertility when $10-20 \times 10^{6}$ spermatozoa were inseminated. When inseminations performed during the 15 days before laying were also considered, all insemination classes were well separated by their fertility level.

In this time interval, a positive correlation was found between fertility and quantity of spermatozoa inseminated for up to $30 \times 10^{6}$ spermatozoa $(R=0.99, P<0.001)$ (Fig. 4). Fertility increased from 28 to $86 \%$ when the quantity of spermatozoa inseminated increased up to more than $30 \times 10^{6}$.

\section{Discussion}

Captive Houbara bustards showed a seasonal breeding pattern and the laying period extended from January to July. Males began displaying well in advance of laying of eggs and continued to display long after the termination of laying. The primary proximate factor triggering sexual maturation could be the annual cycle of the photophase, but temperature seemed to play an important role. Rainfall temperature could act as secondary 'zeitgebers', and high temperature could be the major factor terminating the breeding season (Saint Jalme et al., 1992).

There is a correlation between testicular production of spermatozoa and testes weight (Sauveur, 1982). Even if the concentration of spermatozoa in the ejaculate does not exactly reflect testis sperm production (de Revier, 1982), it is probable that the mean curve of seasonal change in sperm concentration reflects the seasonal variation in testes size. The fluctuation in sperm concentrations, particularly the decreases observed at the beginning of March and in the middle of April were synchronous with two peak temperatures. In adult chickens, El Jack and de Revier (1975, in de Revier, 1982) noticed a decrease in sperm production in response to drastic thermal variation followed by a swift return to normal values.

Reproductive parameters of females from the two subspecies are quite similar but $C$. $u$. macqueenii presented, on average, 


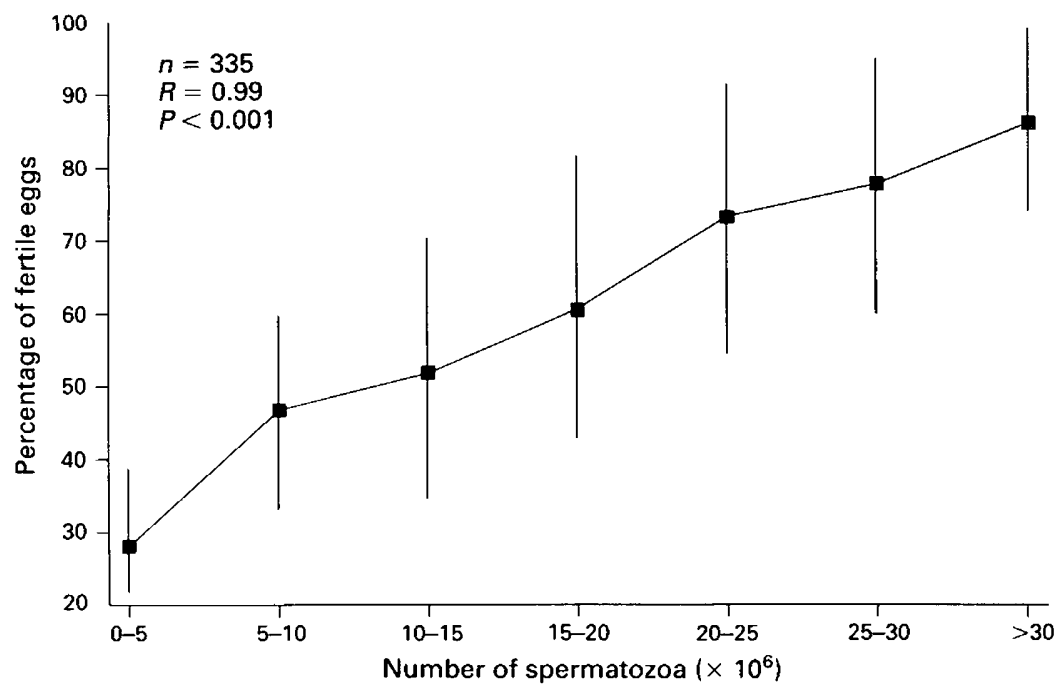

Fig. 4. Relationship between number of spermatozoa inseminated in the interval of time (3-15 days) before laying and fertility ( $\% \pm 95 \%$ confidence interval) in Houbara bustards (Chlamydotis undulata).

better reproductive capacities, for example greater clutch size and smaller inter-clutch intervals. The limited number of birds investigated did not allow determination of whether these differences were subspecific or reflected only inter-individual variation. The morphological difference between the two subspecies (Cramp and Simmons, 1980), the differences in pattern of display and observations of clutch size in the wild, which shows slight differences between $C$. u. macqueenii and C. u. undulata (Cramp and Simmons, 1980), support the contention that there is an inter-subspecific difference.

The pattern of egg laying in domestic birds is governed by the interaction of two asynchronous factors, the cycle of follicular maturation and a cycle in the neuroendocrine mechanism which regulates the preovulatory release of LH (Sharp, 1980). The neuroendocrine cycle is probably controlled by a circadian oscillator and generates an 'open period' or 'gate' during which preovulatory release of LH may be initiated (Sharp, 1980). According to this hypothesis, domestic species such as hens characteristically lay eggs during an 8-9 h period of the day in sequences with the first egg being laid early in the day and successive eggs being laid later on successive days until the sequence is completed (Sharp, 1980). In Houbara bustards, as $30 \%$ of eggs were laid between $15: 00 \mathrm{~h}$ and 18:00 $\mathrm{h}$, a symmetrical distribution will give the extremity of a $10 \mathrm{~h}$ 'gate' at $14: 00 \mathrm{~h}$ and $24: 00 \mathrm{~h}$ and a laying peak between $18: 00 \mathrm{~h}$ and $20: 00 \mathrm{~h}$.

Time of laying and intervals between oviposition and between ovulations are important parameters to consider when artificial insemination is used. Intervals between oviposition are more easily recorded than is the interval between ovulations and, in many species, these events occur very close together (Sauveur, 1988). Time of ovulation and fertilization are important factors to identify. In chickens, ovulation occurs about $24 \mathrm{~h}$ before laying and fertilization occurs $15 \mathrm{~min}$ following ovilation (Sauveur, 1982). In chicken, only a small quantity of spermatozoa have arrived in the upper part of the oviduct $15 \mathrm{~min}$ after insemination and $24 \mathrm{~h}$ are required for $50 \%$ of the spermatozoa to arrive in the same area where fertilization of eggs occur (Sauveur, 1982). Only inseminations performed at least 2 days before laying can therefore successfully fertilize the chicken egg.

Within a clutch, Houbara bustards laid approximately every $48 \mathrm{~h}$, but it is not known when ovulation occurred. In ravens and ostrichs, laying and ovulation occur every 2 days (Birkhead and Moller, 1992). In sandhill crane, the second egg of the two-egg clutch is laid 3 days after the first egg, and the crane apparently ovulates about $6 \mathrm{~h}$ after the first egg is laid. The egg therefore spends $66 \mathrm{~h}$ in the oviduct (Gee, in Birkhead and Moller, 1992). The ancient murrelet lays its two eggs 8 days apart (Astheimer, 1985) but the second egg is ovulated just $24 \mathrm{~h}$ before oviposition. In Houbara bustards two results support the contention that ovulation occurs more than ( $1-4 \mathrm{~h}$ ) $48 \mathrm{~h}$ before oviposition. First, eggs are laid 2 days apart within a clutch with a shift of several hours between laying times and second, no substantial evidence has emerged to prove that eggs can be fertilized by an insemination performed less than 3 days before laying.

No difference was found in sperm production between the two subspecies. The mean volume of the ejaculate was $0.08 \mathrm{ml}$; the mean sperm concentration was $350 \times 10^{6}$ spermatozoa $\mathrm{ml}^{-1}$, and the mean number of spermatozoa per ejaculate was about $20 \times 10^{6}$. These differences were not significant as there was great intra- and inter-individual variation. However, a comparison can be made with other species. Ejaculate volumes measured during artificial insemination studies of 32 species of bird range from $3 \mathrm{ml}$ in the cassowary to $0.01 \mathrm{ml}$ in several species of small passerine (Moller, 1988), with a strong positive relationship between ejaculate volume and both body and testis size (Moller, 1988, 1991). The mean volume of ejaculate obtained in Houbara bustards is very close to that found in guineafowl (Sauveur, 1988: 0.05-0.25 ml) of approximately the same weight. However, sperm concentration recorded in Houbara bustards is much lower than in guineafowl (Sauveur, 1988: $5 \times 10^{9}-8 \times 10^{9}$ spermatozoa $\mathrm{ml}^{-1}$ ). Sperm 
concentration is unrelated to body size but there is a strong positive correlation between sperm concentration and testis size (Birkhead and Moller, 1992) and for number of spermatozoa per ejaculate (Moller, 1988). In Houbara bustards, intraindividual variation in sperm concentration and in the number of spermatozoa per ejaculate was due largely to seasonal variation in gonadal size. The frequency of semen collection also affects the number of spermatozoa per ejaculate. The number of spermatozoa per ejaculate was highest when collection was made every 3 days. Similar results were obtained with chickens (de Revier, 1985; Sauveur, 1988). This observation can be explained by the fact that after 3 days there is some stabilization of the sperm reserve inside the ductus deferens (de Revier, 1985). However, correlation between number of spermatozoa collected and number of spermatozoa produced by the testes increases with the frequency of collection (de Revier, 1985). In chickens and guineafowl it has been shown (de Revier, 1982) that after more than five collections per week, the total number of spermatozoa collected is close to the total number of spermatozoa produced by gonads per week. The mean quantity of spermatozoa produced per week in fully sexually developed Houbara bustards was $165 \times 10^{6}$. This value is very low in comparison with guineafowl or chicken which produce respectively $4 \times 10^{9}$ (de Revier, 1982) and more than $20 \times 10^{9}$ spermatozoa per week (Sauveur, 1988).

Results of sperm storage duration in vivo were obtained by summarizing all data without taking into account the quality of inseminations. This finding suggests an underestimate at least of the medium sperm storage duration. Good positive correlation was shown between fertility and quantity of spermatozoa inseminated and a direct relationship was found between sperm storage duration and number of spermatozoa inseminated.

Fertility was highest with insemination of more than $10 \times 10^{6}$ spermatozoa between 3 and 6 days before laying (85\% of fertile eggs). It appears that when more than $20 \times 10^{6}$ spermatozoa were inseminated during the 15 days before laying, the fertility reached $50 \%$. Nevertheless, this result is overestimated by the fact that the total number of spermatozoa included several inseminations performed between 15 and 3 days before laying.

If we compare sperm storage duration parameters of Houbara bustards with those of other species, it appears that a median of 10 days and a maximum of 22 days are very close to data recorded in chickens (Sauveur, 1982) or capercaillie. For the latter species, Parker (1989) found that the maximum sperm storage duration after natural copulation was 26 days. The longest known period of sperm storage occurs in domesticated turkeys, with a mean value of 43 days and a maximum of 72 days (Birkhead and Moller, 1992) and the shortest period of maximum sperm storage occurs in the ring dove and is 6 days (Zenone et al., 1979).

Embryo mortality in Houbara bustards increased when inseminations were performed more than 10 days before laying. A decrease in the viability of eggs fertilized by spermatozoa that have been stored for a long time has been shown in numerous species such as turkey, chicken, mallard and Japanese quail (Birkhead and Moller, 1992). In chickens, the maximum duration is 35 days, but the probability of an egg hatching after 20 days is low (Lodge et al., 1971).
Nalbandov and Card (1943) showed that the older the spermatozoa, the earlier the stage of development at which mortality occurs.

The mean percentage of eggs that hatched in $1992(49.2 \%$ or $55.7 \%$, excluding early dead embryos) was relatively low. The results obtained showed that decreasing the interval between insemination and increasing the quantity of spermatozoa inseminated would increase the percentage of eggs hatched to $70 \%$, when embryos that die before 3 days of development are excluded. This level is still low compared to $90 \%$ or more obtained in the poultry industry. Incubation at relatively high altitude $(1450 \mathrm{~m}$ ) (Wisschedijk and Rahn, 1981 in Sauveur, 1988) with a low concentration of $\mathrm{O}_{2}$ and $\mathrm{CO}_{2}$ in air could partly explain the difference.

In conclusion, when male Houbara bustards are fully developed, the best results of fertility and percentage of eggs that hatch would be obtained by collecting semen every 3 days (mean of $39 \times 10^{6}$ spermatozoa per ejaculate), and by inseminating $10 \times 10^{6}$ spermatozoa (an average of four females per ejaculate) every 4 days (all the eggs could receive at least one insemination between 3 and 7 days before oviposition). As inter-clutch interval is relatively stable (about 10 days), it is possible to reduce the frequency of insemination between clutches.

The authors would like to thank the National Commission for Wildlife Conservation and Development of Saudi Arabia and its Managing Director, HRH Prince Saud Al Faisal and Secretary General Prof. A. Abuzinada, for their support and confidence throughout the project. Special thanks goes to Jacques Renaud Manager of NWRC for advice through all stages of our work. The authors wish to thank Abdul Rahman Khoja for organizing many administrative issues, G. Schwede, Y. Van Heezik, P. Seddon and S. Biquand for their critiques on the manuscript and I. Mikaelian and P. McCormick for technical help.

\section{References}

Astheimer LB (1985) Long laying intervals: a possible mechanism and its implications Auk 102 401-409

Birkhead TR (1988) Behavioral aspects of sperm competition in birds Advances in the Study of Behavior 18 35-72

Birkhead TR and Moller AP (Eds) (1992) Sperm Competition in Birds, Evolutionary Causes and Consequences. Academic Press, London, New York, Tokyo

Brillard JP (1982) Aspects pratiques de l'insemination artificielle des femelles (poules, pintades, dindes). In Fertilité et Insémination Artificielle en Aviculture pp 77-102 INRA, Versailles

Cramp S and Simmons KEL (Eds) (1980) Family Otididae bustards. In Handbook of the Birds of Europe, the Middle East and North Africa Vol II pp 636-668. Oxford University Press, Oxford

Dementiev GP and Gladkov NA (Eds) (1968) Otides, Bustards. In Birds of the Soviet Union Vol 2 pp 163-195. Translated by A Birron, ZS Cole and ED Gordon. Israel program for Scientific Translations, Jerusalem

de Revier M (1982) Differents aspects de l'elevage des reproducteurs males (coqs, pintades) utilisés en insemination artificielle. Fertilité et Insémination Artificielle en Aviculture pp 25-60 INRA, Versailles

de Revier M (1985) Conduite des coqs reproducteurs de type chair en vue de l'insemination artificielle Compte Rendu de la Conference Avicole WPSA SIMAVIP, Cahier 2 Elevage des Reproducteurs et Insemination Artificielle pp 12-31 Ed. Groupe français de la WPSA Tours

Etchecopar RD and Hue F (Eds) (1978) Otidides - Outardes. Les Oiseaux de Chine, Non Passereaux pp 275-279. Editions du Pacifique, Papeete

Heim De Balzac H and Mayaud N (Eds) (1962) Bustards. In Les Oiseaux du Nord Ouest de l'Afrique pp 109-113. Editions Paul Lechevalier, Paris 
Lake PE (1975) Gamete production and the fertile period with particular reference to domesticated species Symposium, Zoological Society of London 35 225-244

Lodge JR, Fechheimer NS and Jaap RG (1971) The relationship of 'in vivo' sperm storage interval to fertility and embryonic survival in chicken Biology of Reproduction 5 252-257

Mendelssohn H (1980) Development of Houbara (Chlamydotis undulata) populations in Israel and captive breeding. In Symposium papers. The Houbara Bustard, Athens, 1979 pp 131-139 Eds CL Coles and NJ Collar. Sydenhams Printers, Poole

Moller AP (1988) Testes size, ejaculate quality, and sperm competition in birds Biological Journal of the Linnean Society 33 273-283

Moller AP (1991) Sperm competition, sperm depletion, paternal care, and relative testis size in birds American Naturalist 137 882-906

Nalbandov AV and Card LE (1943) Effect of stale sperm on fertility and hatchability of chicken eggs Poultry Sciences 22 218-226

Parker H (1989) Duration of fertility in Capercaillie hens after separation from males Ornis Scandinavica 20 307-310
Saint Jalme M, Paillat P and Gaucher P (1992) Seasonal reproduction and environmental cue in an arid dwelling species: the Houbara bustard (Chlamydotis undulata) Abstracts of $V$ International Symposium on Avian Endocrinology p $99 \mathrm{Ed}$. AFRC Institute of Animal Physiology and Genetics Research, Roslin

Sauveur B (Ed.) (1982) Notion de physiologie de la reproduction femelle en relation avec l'insemination artificielle. Fertilité et Insémination Artificielle en Aviculture pp 61-75 INRA, Versailles

Sauveur B (1988) Reproduction des Volailles et Production d'oeufs 449pp INRA, Paris

Sharp PJ (1980) Female reproduction. Avian Endocrinology pp 435-454 Ed. A Epple and MH Stetson. Academic Press, New York, London

Urban EK, Fry CH and Keith S (Eds) (1986) Family Otididae: bustards. The Birds of Africa Vol II pp 148-179. Academic Press, London

Zenone PG, Sims ME and Erickson CJ (1979) Male ring dove behavior and the defence of genetic paternity American Naturalist 114 615-626 